Saudi Journal of Medical and Pharmaceutical Sciences

Abbreviated Key Title: Saudi J Med Pharm Sci

ISSN 2413-4929 (Print) |ISSN 2413-4910 (Online)

Scholars Middle East Publishers, Dubai, United Arab Emirates

Journal homepage: https://saudijournals.com/sjmps

Original Research Article

\title{
Ramadan Focused Educational Program among Patients with Type 2 Diabetes
}

\author{
Hind Asbar ${ }^{*}$, Sana Rafi, Ghizlane El Mghari, Nawal El Ansari \\ Department of Endocrinology, Diabetes, Metabolic diseases and Nutrition, Mohammed VI University Hospital, Marrakesh, Morocco
}

\begin{tabular}{ll}
\hline DOI: $10.36348 /$ sjmps.2020.v06i05.004 & | Received: 11.05 .2020 | Accepted: 18.05.2020 | Published: 21.05 .2020 \\
*Corresponding author: Hind Asbar &
\end{tabular}

\section{Abstract}

Ramadan is the ninth month of the Islamic calendar during which Muslims must fast from dawn to sunset. Islam exempts ill and weak people from fasting including high risk patients with diabetes, but a number of them fast regardless of medical advice. Ramadan focused education is a key component for patients with type 2 diabetes (T2D). The aim of our study was to assess the knowledge and awareness of type 2 diabetic patients after a Ramadan focused educational program. This cross sectional study was carried out on patients with type 2 diabetes willing to benefit from a Ramadan focused educational program, 2 weeks prior to Ramadan. Data on sociodemographic characteristics, lifestyle habits, physical activity, blood glucose monitoring, hypoglycemia and hyperglycemia management were obtained. After Ramadan, a questionnaire was used to collect information on patients' knowledge regarding Ramadan education. Results showed that this study included 176 type 2 diabetic patients with a response rate of $62 \%$. The mean age of our patients was $58 \pm 8,1$ years. The mean duration of diabetes was $4 \pm 6$ years. Antidiabetic treatment adjustment was done in $69 \%$ of patients, $53 \%$ of patients were advised not to fast during Ramadan but $35 \%$ of them decided to fast anyway. Patients monitored their blood glucose in $68 \%$ of cases and $30 \%$ of patients were aware of hypoglycemia and interrupted fasting in $6 \%$ of cases.

Keywords: Diabetes, Education, Ramadan, Fasting, Islam, Type 2 diabetes.

Copyright @ 2020: This is an open-access article distributed under the terms of the Creative Commons Attribution license which permits unrestricted use, distribution, and reproduction in any medium for non-commercial use (NonCommercial, or CC-BY-NC) provided the original author and source are credited.

\section{INTRODUCTION}

In Muslim religion, Ramadan is the ninth month of the Islamic calendar and is one of the five pillars of Islam. During this holy month, all adult healthy individuals must abstain from eating and drinking from dawn to sunset. Islam exempts people with chronic diseases from fasting if it represents any danger for one's health [1]. Type 2 diabetes is one of the most common chronic diseases. Fasting risks in patients with diabetes depends on glycemic control, associated comorbid conditions, such as renal insufficiency, advanced micro and macrovascular complications among other complications [2]. The radical lifestyle change during this month, might affect diabetic patients whether they choose to fast or not. Ramadan focused diabetes education is a structured program aiming to guide diabetic patients through this holy month avoiding them serious complications [3]. The aim of our study is to assess the knowledge and awareness of type 2 diabetic patients after a Ramadan focused educational program.

\section{Material AND Methods}

It was a cross sectional study that recruited type 2 diabetic patients that beneficiated from a Ramadan focused educational program, 2 weeks prior to Ramadan 2019, conducted in the endocrinology, diabetes and metabolic diseases department of Mohammed VI university hospital of Marrakesh. The study included adult Muslim patients with type 2 diabetes who attended our structure. Exclusion criteria were patients with type 2 diabetes who suffer from severe complications (such as unstable heart disease or severe renal insufficiency), patients with type 1 diabetes and pregnant women. It included data collection on sociodemographic characteristics, lifestyle habits, physical activity, blood glucose monitoring, hypoglycemia and hyperglycemia management, and associated comorbidities. Risk assessment of fasting based on the International Diabetes Federation (IDF) and Diabetes and Ramadan (DAR) risk categories, was obtained during individual interviews. Small groups of 8 to 10 patients beneficiated from an adapted version of Measured Approach for Diabetes and Ramadan (MADAR) education. One month after Ramadan, 
patients were then called on the phone to give feedback on the educational program. A questionnaire was used to collect information on fasting according to medical advice, the frequency of use of glucose monitoring, the frequency of hypo and hyperglycemia and its management and finally on the need of the patients of more information about Ramadan and diabetes in our educational program.

\section{RESUlTS}

A total of 176 patients were enrolled in our study. $128(72,7 \%)$ were women and $48(27,3 \%)$ were men. The mean age was $58 \pm 8,1$ years. The mean duration of diabetes was $4 \pm 6$ years. Associated co morbidities frequency of hypertension, dyslipidemia and cardiac disease was 34\%, 20\% and 6\% respectively. For their diabetes treatment, patients were on oral glucose lowering agents in $55,1 \%$ of cases, on insulin in $21 \%$ of cases, on combined oral and insulin therapy in $14,8 \%$ and finally $9,1 \%$ were on a diet alone. The overall demographic and clinical data is shown in Table-1.

Table-1: Overall demographic and clinical data

\begin{tabular}{|l|l|}
\hline Parameters & $\mathbf{N}^{\circ}(\%)$ \\
\hline Participants & $176(100)$ \\
\hline Male & $48(27,3)$ \\
\hline Female & $128(72,7)$ \\
\hline Age (years) & \\
$<50$ & $43(24,4)$ \\
$\geq 50$ & $133(75,5)$ \\
mean age \pm SD & $58 \pm 8,1$ \\
\hline Duration of DM (years) & $72(41)$ \\
$0-5$ & $47(26,7)$ \\
$6-10$ & $57(32,3)$ \\
$>10$ & \\
\hline Comorbidities & $60(34)$ \\
Hypertension & $35(20,4)$ \\
Dyslipidemia & $12(6,8)$ \\
Cardiac disease & \\
\hline Treatment of DM & $16(9,1)$ \\
Diet and exercise only & $97(55,1)$ \\
Oral medications & $37(21)$ \\
Insulin only & $26(14,8)$ \\
Oral medications + insulin
\end{tabular}

During our program, 81 patients $(46 \%)$ were allowed to fast while 95 patients $(54 \%)$ were advised not to fast. Most of patients $(69,3 \%)$ had therapeutic adjustment regarding dosage and timing of medication, especially in the fasting group.

The response rate in our survey was of $62 \%$, with 53 patients $(48,1 \%)$ in the fasting group and 57 patients $(51,8 \%)$ in the non-fasting group. In the latter, $35 \%$ of responders said they fasted against medical advice. Among them, $15 \%$ said that they were not convinced by the medical risks of fasting, while $75 \%$ said that they were convinced but they were willing to take those risks due their religious or social commitment.

Glucose monitoring was done by most patients in $68 \%$ of cases. Blood glucose levels were checked once a day in most patients or when feeling signs of hypo or hyperglycemia. Symptoms of hypoglycemia were experienced in $30 \%$ of cases. Fasting was interrupted in case of severe hypoglycemia in $6 \%$ of patients. Symptoms of hyperglycemia were recognized in $27 \%$ of cases. $3 \%$ of patients reported consulting in the emergency room in the face of high blood sugar.

Regarding dietary measures, $92 \%$ of responders said they took enough fluids during Ramadan. Consumption of sweets and food with high glycemic index was reported in $23 \%$ of cases. Physical exercise including taraweeh prayer that is considered as moderate physical activity was performed by $35 \%$ of patients. Changes in patients' behavior during Ramadan are shown in Table-2.

Table-2: Changes in patients' behavior during Ramadan

\begin{tabular}{|l|l|}
\hline Parameter & $\mathbf{N}^{\circ}(\%)$ \\
\hline Fasting during Ramadan & $37(33,6)$ \\
No & $73(66,3)$ \\
Yes & $20(18,1)$ \\
Fasting against medical advice & $63(68,4)$ \\
\hline Glucose monitoring & $13(20,6)$ \\
More than one time a day & $28(44,4)$ \\
Once a day & $22(35)$ \\
Once or more a week & \\
\hline Symptoms of hypoglycemia awareness & $92(100)$ \\
Yes & $0(0,0)$ \\
No & \\
\hline Occurrence of hypoglycemia & $28(30,4)$ \\
Yes & $64(69,6)$ \\
No & \\
\hline Attitude in the face of hypoglycemia & $86(93,5)$ \\
Continued fasting & $6(6,5)$ \\
Stopped fasting & $0(0,0)$ \\
Visited doctor & $87(94,6)$ \\
\hline Symptoms of hyperglycemia awareness & \\
Yes & $5(5,4)$ \\
No & $25(27,2)$ \\
\hline Occurrence of hyperglycemia & $67(72,8)$ \\
Yes & $87(94,6)$ \\
No & $2(2,2)$ \\
\hline Attitude in the face of hyperglycemia \\
Continued fasting & $3(3,2)$ \\
Stopped fasting & \\
Visited doctor & $21(22,8)$ \\
\hline Dietary & $85(92,3)$ \\
Sweet foods consumption & \\
Enough fluid intake & \\
Exercise (including taraweeh prayer) & $32,7)$ \\
\hline
\end{tabular}


The overall feedback of responders in our study was positive. A number of them said being more aware of symptoms of hypo or hyperglycemia. They also said knowing when to break the fast to avoid complications. And finally, 35\% of patients reported that they felt the need of more information for diabetes management during Ramadan.

\section{DISCUSSION}

Fasting during Ramadan in poorly controlled diabetic patients may potentially cause adverse events. The radical lifestyle changes during this month include abstaining from eating, drinking and taking oral medication during long hours of fasting that vary according to seasons [4]. In our study, Ramadan 2019 took part from $7^{\text {th }}$ May to $6^{\text {th }}$ June. It was a relatively hot period in Marrakesh and daylight fasting hours reached up to 16 hours.

All of these changes represent a big challenge for medical health providers, as they need to emphasize on pre-Ramadan education. Several studies showed the importance of this Ramadan focused structured education [5-10]. The key components are risk quantification, blood glucose monitoring, nutritional advice, exercise advice, medication adjustments and knowing when to break the fast to minimize acute complications [10].

The EPIDIAR study is to date the largest study to investigate diabetic patients during Ramadan; it showed that $79 \%$ of patients with type 2 diabetes fasted during Ramadan [11]. In our study $64 \%$ of patients reported fasting. Among them were those who decided to fast against medical advice, they represented $35 \%$ of the non fasting group. A recent study conducted in the UAE showed that $76 \%$ of high risk patients who were advised not to fast decided to challenge their physicians' decision [12]. This was associated with higher risk of hypoglycemia, acute illness or diabetic ketoacidosis [12].

A large number of studies showed the importance of Ramadan related education in having beneficial effect on glycemic control [13, 14]. A study conducted in Saudi Arabia showed that recognition of symptoms of hypoglycemia and hyperglycemia as well as blood glucose monitoring was higher in patients who received education before Ramadan [5].

Regarding nutrition, diabetic patients during Ramadan experience a drastic change in diet and food intake. Whether they fast or not, they can consume a large amount of sweet foods and meals rich in carbohydrates and fats. One study that took part in the UK showed evidence of benefit of Ramadan focused diabetes education; patients who received dietary advice had a mean weight loss of $0.7 \mathrm{~kg}$ after Ramadan, compared to weight gain of $0.6-\mathrm{kg}$ in the control group
$(\mathrm{p}<0.001)$.The educational program also helped to sustain HbA1c 12months after attending the program [15]. In our study, most patients reported consuming enough fluids in this hot period of fasting and trying to keep a balanced and healthy diet.

\section{CONCLUSION}

Ramadan education is a key component in diabetes management and a much-needed approach that requires involvement of both patients and medical health providers. Our study shows how a structured educational program can have an impact on patients' knowledge and awareness.

\section{REFERENCES}

1. The Holy Quran, Surat Al-Baqarah Aya 184.

2. Ahmad, J., Pathan, M. F., Jaleel, M. A., Fathima, F. N., Raza, S. A., Khan, A. A., ... \& Sheikh, A. (2012). Diabetic emergencies including hypoglycemia during Ramadan. Indian journal of endocrinology and metabolism, 16(4), 512.

3. Hassanein, M. (2015). Ramadan focused diabetes education; a much needed approach. Journal Pak Med Assoc, 65(5 Suppl 1), S76-S78.

4. Hui, E., Bravis, V., Hassanein, M., Hanif, W., Malik, R., Chowdhury, T. A., ... \& Devendra, D. (2010). Management of people with diabetes wanting to fast during Ramadan. BMJ, 340, c3053.

5. Al-Musally, R. M., Al-Sardi, M. A., Al-Elq, Z. A., Elahi, A. H., Alduhailan, R. K., Al-Elq, M. A., ... \& Al-Elq, A. H. (2017). Health education to diabetic patients before the start of Ramadan: Experience from a teaching hospital in Dammam. Journal of family \& community medicine, 24(2), 111.

6. Almalki, M. H., Hussen, I., Khan, S. A., Almaghamsi, A., \& Alshahrani, F. (2018). Assessment of Ramadan education and knowledge among diabetic patients. Clinical Medicine Insights: Endocrinology and Diabetes, 11, 1179551417751611.

7. Al-Arouj, M., Bouguerra, R., Buse, J., Hafez, S., Hassanein, M., Ibrahim, M. A., ... \& Al-Madani, A. (2005). Recommendations for management of diabetes during Ramadan. Diabetes care, 28(9), 2305-2311.

8. Al-Arouj, M., Assaad-Khalil, S., Buse, J., Fahdil, I., Fahmy, M., Hafez, S., ... \& Al-Madani, A. (2010). Recommendations for management of diabetes during Ramadan: update 2010. Diabetes care, 33(8), 1895-1902.

9. Ibrahim, M., Al Magd, M. A., Annabi, F. A., Assaad-Khalil, S., Ba-Essa, E. M., Fahdil, I., ... \& Shera, S. (2015). Recommendations for management of diabetes during Ramadan: update 2015. BMJ Open Diabetes Research and Care, 3(1), e000108. 
10. Hassanein, M., Al-Arouj, M., Hamdy, O., Bebakar, W. M. W., Jabbar, A., Al-Madani, A., ... \& Omar, M. A. K. (2017). Diabetes and Ramadan: practical guidelines. Diabetes research and clinical practice, 126, 303-316.

11. Salti, I., Bénard, E., Detournay, B., BianchiBiscay, M., Le Brigand, C., Voinet, C., \& Jabbar, A. (2004). A population-based study of diabetes and its characteristics during the fasting month of Ramadan in 13 countries: results of the epidemiology of diabetes and Ramadan 1422/2001 (EPIDIAR) study. Diabetes care, 27(10), 23062311.

12. Afandi, B., Kaplan, W., Al Kuwaiti, F., Al Dahmani, K., \& Nagelkerke, N. (2017). "Ramadan challenges: Fasting against medical advice. Journal of Fasting and Health, 5(3), 133137.

13. Thongsai, S., \& Youjaiyen, M. (2013). The longterm impact of education on diabetes for older people: a systematic review. Global journal of health science, 5(6), 30.

14. Farid, D., Rosenberg, E., \& Bartlett, G. (2014). Importance of education in managing type 2 diabetes during Ramadan. Canadian Family Physician, 60(6), 508-510.

15. Bravis, V., Hui, E., Salih, S., Mehar, S., Hassanein, M., \& Devendra, D. (2010). Ramadan Education and Awareness in Diabetes (READ) programme for Muslims with Type 2 diabetes who fast during Ramadan. Diabetic Medicine, 27(3), 327-331. 